QUARTERLY TECHNICAL PROGRESS REPORT

(Eighth Quarter)

\title{
ADVANCED OIL RECOVERY TECHNOLOGIES FOR IMPROVED RECOVERY FROM SLOPE BASIN CLASTIC RESERVOIRS, NASH DRAW BRUSHY CANYON POOL, EDDY COUNTY, NM
}

DOE Cooperative Agreement No. DE-FC-95BC14941

\author{
Strata Production Company \\ P.O. Box 1030 \\ Roswell, NM 88202 \\ (505) 622-1127
}

Date of Report:

Award Date:

Anticipated Completion Date:

Award Amount for Current Fiscal Year:

Award Amount for Budget Period I:

Name of Project Manager:

Contracting Officer's

Representative:

Reporting Period:
October 30, 1997

September 25, 1995

September 24, 1998 - Budget Period I

September 25, 2001 - Budget Period II

$\$ 2,011,213$

$\$ 3,354,067$

Mark B. Murphy

Mary Beth Pearse

July 1, 1997 - September 30, 1997

US/DOE Patent Clearance is not required prior to the publication of this document. 


\section{OBJECTIVE}

The overall objective of this project is to demonstrate that a development program-based on advanced reservoir management methods-can significantly improve oil recovery. The plan includes developing a control area using standard reservoir management techniques and comparing its performance to an area developed using advanced reservoir management methods. Specific goals are (1) to demonstrate that an advanced development drilling and pressure maintenance program can significantly improve oil recovery compared to existing technology applications and (2) to transfer these advanced methodologies to oil and gas producers in the Permian Basin and elsewhere throughout the U.S. oil and gas industry.

\section{SUMMARY OF TECHNICAL PROGRESS}

This is the eighth quarterly progress report on the project. Results obtained to date are summarized.

\section{MANAGEMENT AND PROJECT PLANNING}

Geological, engineering, geophysical data have been analyzed and entered into a geological model, and reservoir simulation runs for the initial pilot area have been performed. The 3-D seismic data have been interpreted, and areas have been identified for targeted drilling. The first well based on the seismic data was drilled in March 1997, and a second well was drilled in September 1997. Locations for all of the wells in the Nash Draw Pool (NDP) are shown in Figure 1.

Strata requested a 12-month no-cost extension for Phase I activities that included several modifications in the original statement of work. During this quarter, Strata received approval from the DOE for the extension and modifications.

\section{GEOLOGY}

To evaluate the targeted drilling of the seismic anomalies, the next well to be drilled at the Nash Draw Project was based primarily on seismic attributes. After evaluating drainage, cultural obstructions, well spacing and anomaly size and amplitude, it was decided to drill the NDP Well \#38. This well is located in the SE/SW Section 13, T23S-R29E and would evaluate an anomaly trend that runs north to south from NDP Well \#29 into Section 24 to the south. As of September 30, 1997, NDP Well \#38 has been drilled, and logs and cores were being obtained. A complete analysis of this well will be presented in the next quarterly report. 


\section{ENGINEERING}

The NDP Well \#29 has been production tested since June 1, 1997. Testing has confirmed that the "L" zone is partially pressure depleted as indicated during the Repeat Formation Test performed on the zone at 6525' that indicated a stabilized bottom hole pressure of 1905 psi. The initial gasoil ratio was over $8 \mathrm{MCFG}$ per barrel of oil. A GOR of this magnitude is typical of a well that has been on production for over a year. By October 1, 1997 the GOR has increased to 10.7 to 1. A typical well achieves a GOR of 10 to 1 after approximately 20 months of production.

The pressure depletion experienced in NDP Well \#29 prompted a review of the production data to determine the interference between wells, drainage areas and the effect on ultimate primary recovery. To evaluate the history of the reservoir the completion sequence was determined, an initial GOR was determined for each well, a Cumulative Production vs. Rate curve for each well was plotted, the ultimate primary production was estimated from the decline curves, primary recovery per acre was estimated from the log analysis, a indicated drainage area was estimated by dividing the ultimate recovery by the recovery per acre value, and a ratio of indicated Drainage Area vs. Allocated Acreage was calculated. A summary of this data is presented in the following table:

\begin{tabular}{|c|c|c|c|c|c|c|c|}
\hline $\begin{array}{c}\text { Well } \\
\text { No. \& } \\
\text { Order }\end{array}$ & $\begin{array}{c}\text { Initial } \\
\text { GOR } \\
\text { MCFG/BO }\end{array}$ & $\begin{array}{c}\text { Cum. vs. Rate } \\
\text { Plot }\end{array}$ & $\begin{array}{c}\text { Ultimate } \\
\text { Primary } \\
\text { Recovery }\end{array}$ & $\begin{array}{c}\text { Recovery } \\
\text { BO/Acre }\end{array}$ & $\begin{array}{c}\text { Indicated } \\
\text { Drainage } \\
\text { Area, Ac. }\end{array}$ & $\begin{array}{c}\text { Acreage } \\
\text { Allocation } \\
\text { Acres }\end{array}$ & $\begin{array}{c}\text { Indicated/ } \\
\text { Allocated } \\
\text { Ratio }\end{array}$ \\
\hline $1-2$ & 1.98 & $\begin{array}{c}\text { Multiple } \\
\text { slopes }\end{array}$ & 63,346 & 2,758 & 22.97 & 40 & 0.5742 \\
\hline $5-8$ & 1.17 & Straight & 73,846 & 2,926 & 25.24 & 40 & 0.6309 \\
\hline $6-5$ & 1.37 & $\begin{array}{c}\text { Multiple } \\
\text { slopes }\end{array}$ & 50,980 & 2,627 & 19.41 & 30 & 0.6469 \\
\hline $9-1$ & 1.59 & $\begin{array}{c}\text { Multiple } \\
\text { slopes }\end{array}$ & 52,785 & 1,545 & 34.16 & 60 & 0.5694 \\
\hline $10-3$ & 1.82 & $\begin{array}{c}\text { Multiple } \\
\text { slopes }\end{array}$ & 44,516 & 1,613 & 27.60 & 60 & 0.4600 \\
\hline $11-6$ & 1.19 & $\begin{array}{c}\text { Multiple } \\
\text { slopes }\end{array}$ & 143,196 & 2,896 & 49.45 & 80 & 0.6181 \\
\hline $12-14$ & 14.03 & Steep slope & 76,883 & 2,957 & 26.00 & 60 & 0.4333 \\
\hline $13-4$ & 1.48 & $\begin{array}{c}\text { Multiple } \\
\text { slopes }\end{array}$ & 89,698 & 2,613 & 34.33 & 80 & 0.4291 \\
\hline $14-7$ & 2.59 & Straight & 91,147 & 3,085 & 29.55 & 60 & 0.4924 \\
\hline $15-10$ & 2.73 & Straight & 117,895 & 2,964 & 39.78 & 80 & 0.4972 \\
\hline $19-11$ & 1.47 & Straight & 145,086 & 2,205 & 65.80 & 80 & 0.8225 \\
\hline $20-9$ & 5.93 & Steep slope & 45,620 & 1,937 & 23.55 & 60 & 0.3925 \\
\hline $23-13$ & 5.72 & Steep slope & 49,204 & 1,710 & 28.77 & 60 & 0.4796 \\
\hline
\end{tabular}




\begin{tabular}{|c|c|c|c|c|c|c|c|}
\hline $24-12$ & 2.54 & Straight & 138,031 & 3,338 & 41.35 & 80 & 0.5169 \\
\hline $25-14$ & 4.69 & Steep slope & 8,415 & 1,178 & 7.14 & 40 & 0.1786 \\
\hline $29-16$ & 8.06 & Steep slope & 52,204 & 2,640 & 19.77 & 60 & 0.3296 \\
\hline
\end{tabular}

The pressure depletion evidenced in NDP Well \#29 indicates that some of the main producing zones are continuous over large distances. NDP Well \#29 is 2,214 ft. from the NDP Well \#5, $1,617 \mathrm{ft}$. from NDP Well \#10, and 2,577 ft. from NDP Well \#23. At this time it is not known which wells are in communication with NDP Well \#29, but there should be a change in slope of the Cumulative vs. Rate Curve for the effected wells after NDP Well \#29 has produced for a few months.

By plotting Cumulative Production vs. Rate (log scale), three groups of wells were identified. The first group is characterized by a straight line with a moderate slope. This type of curve is indicative of a well that is in a large reservoir with minor or no interference with other wells. The wells in this group are NDP Wells \#5, \#14, \#15, \#19 and \#24. These wells are located on the outside of the developed area and have other producing wells on only one or two sides.

The second group of wells is characterized by initial production similar to the first group of wells with a increase in the slope of the curve when interference effects the production rate. The wells in this group are NDP Wells \#1, \#6, \#9, \#10, \#11, and \#13. All of these wells, except NDP Well $\# 13$, are inside wells that are offset by two or more producers. NDP Well \#13 is offset by three high cumulative production wells on the south and east sides and is open on the north and west sides. This group of wells is developed on approximately 40-acre spacing.

The third group of wells is characterized by a steep slope of the Cumulative Production vs. Rate curve. This group of wells exhibit high initial GORs associated with partial pressure depletion and low initial oil production rates. The wells in this group are NDP Wells \#12, \#20, \#23, \#25, and \#29.

An ultimate primary recovery volume was estimated for each well by projecting the decline curve to the economic limit. This volume was then divided by the recovery per acre estimated from the $\log$ analysis. The resulting value indicates the number of acres being drained by each well. By comparing the indicated drainage area to the allocated area (40- or 80-acre spacing) a drainage ratio can be calculated. The eight (8) wells with initial GORs of less than $2 \mathrm{MCFG} / \mathrm{BO}$ indicate a $60 \%$ ratio from the indicated drainage area to the allocated drainage area. The remaining eight (8) wells with high GORs indicate a decreasing drainage ratio from $60 \%$ to $20 \%$. (see Figure 2)

The conclusion from this analysis and the basis for future investigation is:

1) Wells drilled on 40 -acre spacing exhibit interference.

2) Pressure depletion can occur over distances greater than 1,600 feet. 
3) Some wells exhibit little or no effects of interference. This may be attributed to compartmentalization or a large reservoir volume in relation to the amount of interference.

4) Wells on 40-acre spacing may be recovering less than $60 \%$ of the recoverable oil due to the laminated and discontinuous nature of the reservoir.

The NDP Well \#38 was spudded on September 12, 1997, drilled to a depth of 7,200 feet with no difficulties, and production casing was set and cemented on October 3, 1997. The surface location of the well is $330 \mathrm{ft}$. FSL \& $2450 \mathrm{ft}$. FWL in section 13, T23S-R29E, approximately 1,777 feet south-southwest of the NDP Well \#29. This well was drilled on a seismic anomaly that indicated high amplitude values for the " $\mathrm{K}$ " interval and high negative amplitude values in the "L" interval. A complete analysis of this well will be included in the next quarterly report.

Production and decline curves have been updated through September 1, 1997. Production for the month of August 1997 averaged 301 BOPD, 2,925 MCFGD and 1,168 BWPD.

\section{RESERVOIR CHARACTERIZATION/RESERVOIR SIMULATION}

Activities of the Reservoir Characterization/Simulation Team for the third quarter of 1997 were focused on fine-tuning the history match of the simulation model and updating the gas injection forecasts.

Having achieved a rough history match during the preceding quarter, we initiated a systematic investigation of the impact on the match of the variability of the following parameters:

- fracture transmissibility

- effective drainage area rock matrix transmissibility

- well drainage area pore volume

- water and gas relative permeability

- well PIs

The parameters above are listed in the order of decreasing uncertainty. The results of this study will be presented in the annual report for FY 1997. The purpose of this effort was to determine which of the parameters is likely to have the greatest effect on the reliability of forecasts with the model. With only five wells in the pilot node (see Fig. 1), there are not enough data to perform a statistical analysis of model uncertainty.

Two forecasts were also rerun. In the first scenario, NDP Well \#1 was converted to a gas injector at the end of the historical data, April 1, 1997. NDP \#1 was controlled by a constraint on flowing bottomhole pressure of 3000 psi. A two-year forecast run was made which indicates that repressuring effects would only be felt in the drainage area of NDP \#1, and that there would be very little effect on oil production in the neighboring wells. Moreover, gas breakthrough at NDP \#5 would probably be experienced during the first year of gas injection. 
In the second scenario, NDP \#1 was converted to a gas injector after only one year of oil production. In this case, the average pressure in the pilot node remains above $1500 \mathrm{psi}$, and the remaining producers experience a very stable decline in production through April 1, 1997.

The details of both of these cases will be presented in the second annual project report.

\section{TECHNOLOGY TRANSFER}

Transferring technical information generated during the course of this project is a prime objective of the project. Toward this objective, Strata has participated in several meetings and workshops to promote the dissemination of information generated during this quarter. A summary of these activities is outlined.

IEA Paper - A paper entitled "Optimizing Oil Recovery from a Complex, Low Permeability Turbidite Reservoir" was presented at the $199718^{\text {th }}$ International Energy Agency Workshop and Symposium on Enhanced Oil Recovery held in Copenhagen, Denmark in September, 1997.

SPE Paper - A paper entitled "Reservoir Characterization as a Risk Reduction Tool at the Nash Draw Pool," was finalized for presentation at the SPE Annual Technical Conference and Exhibition in San Antonio, Texas in October, 1997.

SPE Paper - A paper entitled "Implementation of a Virtual Enterprise for Reservoir Management Applications," was finalized for presentation at the SPE Annual Technical Conference and Exhibition in San Antonio, Texas in October, 1997.

Workshop - In September, a workshop including results from the Nash Draw project was held in Hobbs, New Mexico in conjunction with a reservoir characterization symposium coordinated by the PRRC at New Mexico Tech. The geological interpretation, integration of the seismic and reservoir data, and a discussion of the reservoir petrography and composition as it relates to log analysis and reservoir productivity were covered. The full core from NDP Well \#23 was also available for inspection by attendees at the presentation and workshop.

Workshop - BDM Oklahoma and the Department of Energy will hold a workshop entitled "Advanced Applications of Wireline Logging for Improved Recovery" in November 1997. Strata's project will be participant in the workshop.

Internet Homepage: The Nash Draw Website can be accessed at http://baervan.nmt.edu/REACT/Links/nash/strata.html. The current site includes a summary report and an interactive map with well logs and historical production for wells in the NDP. 


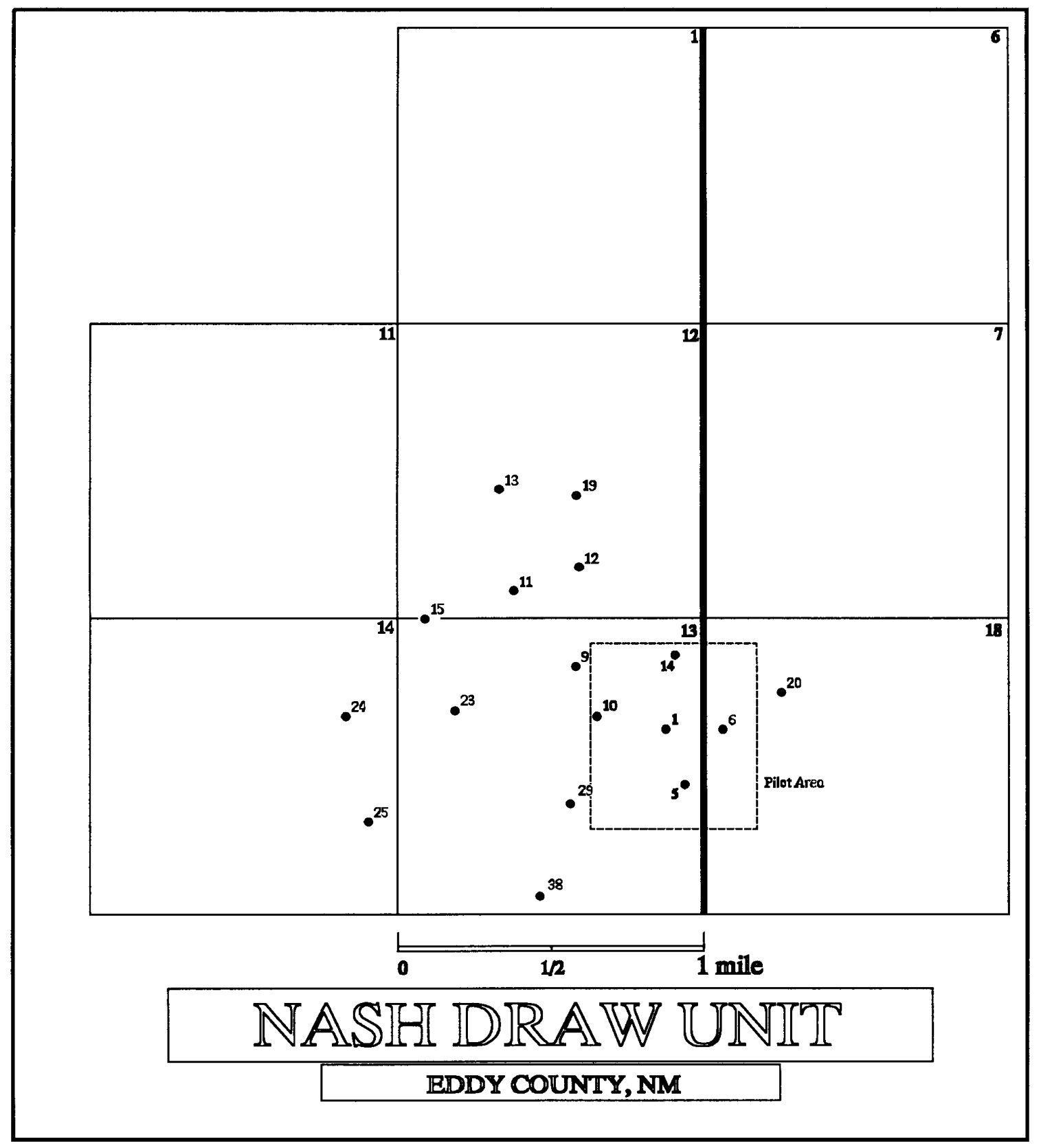

Figure 1. Well locations at the Nash Draw Pool. 


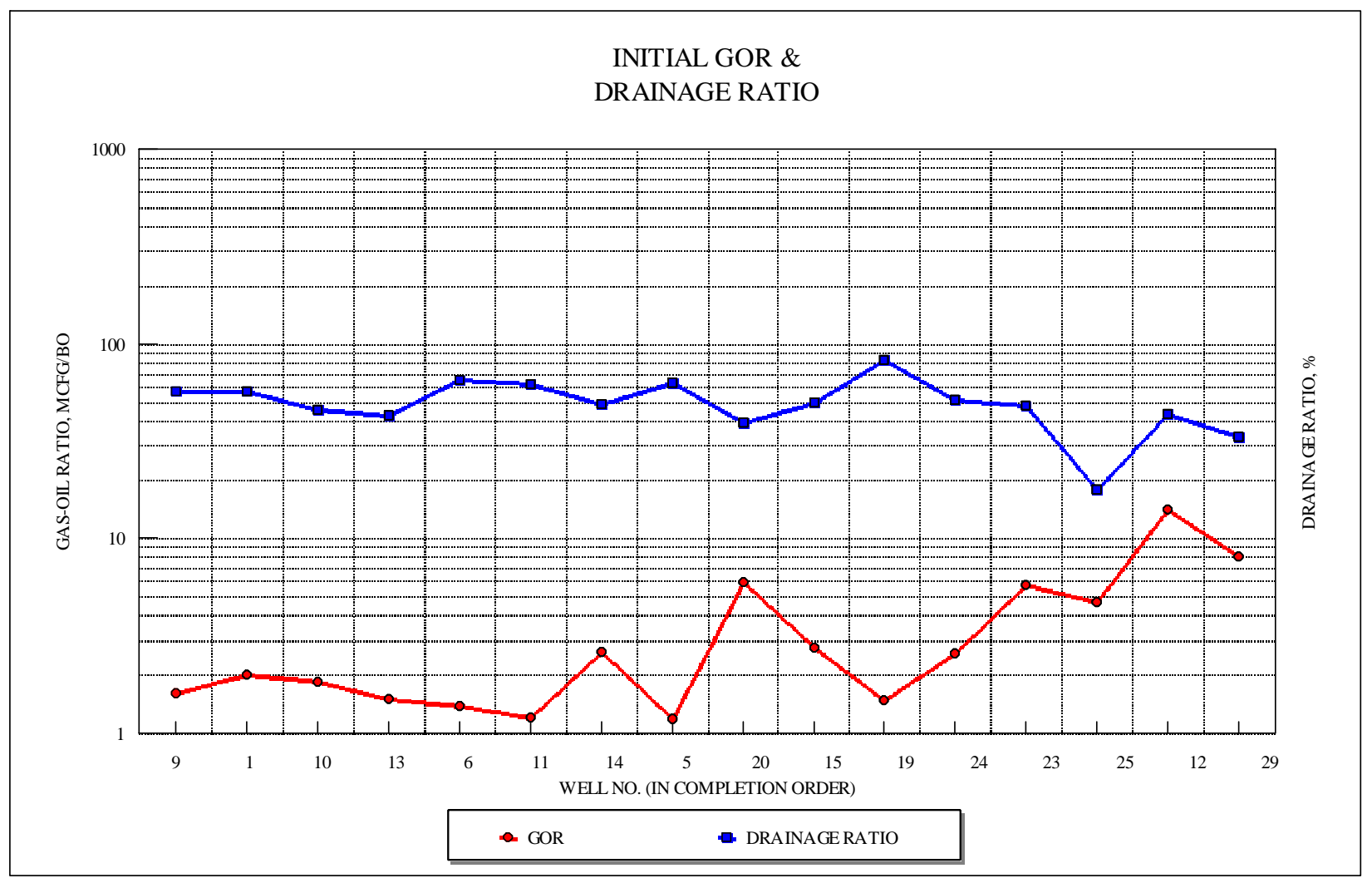

Figure 2. Initial Gas-Oil Ratio and Drainage Ratio. 